that could exclude entry, only trachoma and favus were diagnosed with much regularity.

Kraut's second theme deals with the majority who got through Ellis Island and the other port screening centres. Except for a chapter on the Chinese in San Francisco, Kraut's focus is principally New York City, a quarter of whose population in 1860 had been born in Ireland. Half a century later, a quarter of the city's population was Jewish, and mostly first generation. Those who were not Jewish or Irish often came from Italy. Kraut analyses some of the health problems faced by each of these groups: exploitation in the workplace, poverty, overcrowding and insanitary living conditions, inadequate access to medical and

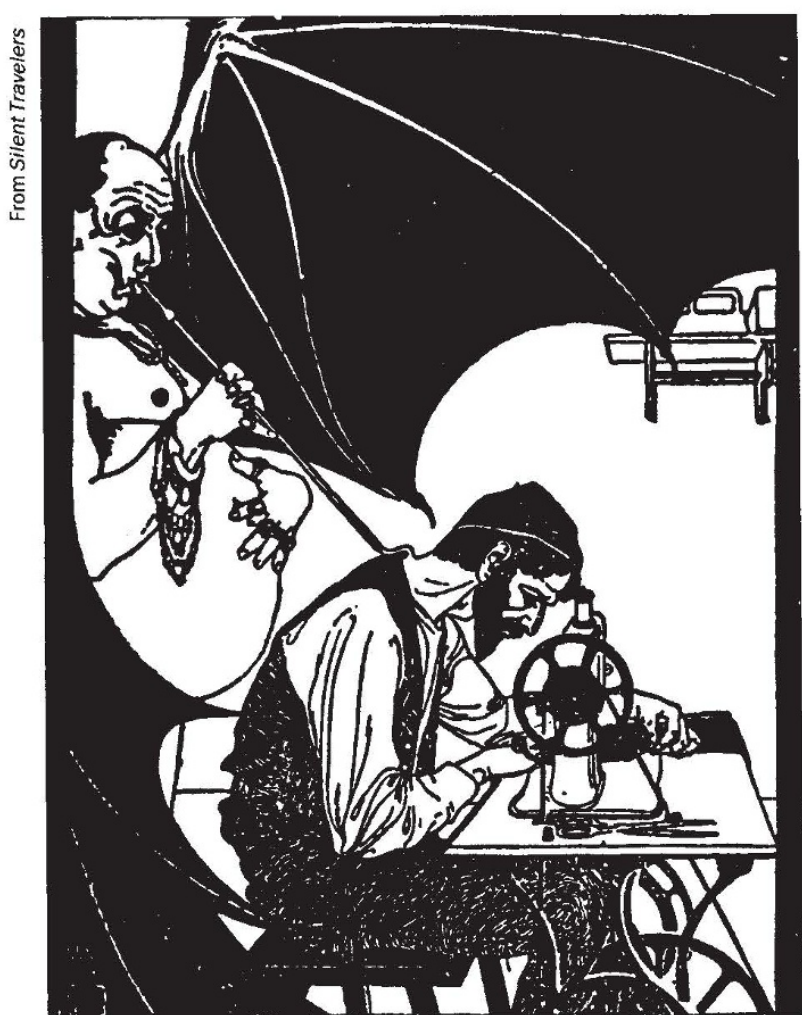

Tuberculosis sucking the breath from a Jewish tailor's body (Sanatorium, 1907).

nursing services, anxiety and disillusionment (almost half the Italian immigrants ultimately returned to Europe). He examines strategies taken by and for new Americans to cope with disease, from imported traditional remedies to hospitals and health visitors.

Immigrant groups usually suffered excessive morbidity and mortality when compared with those born in the United States. Kraut's volume is littered with figures and the occasional table, but he seems less interested in trends than in snapshots of particular mortalities at random times. Sometimes the numbers cry out for probing, as when Italians are quoted as having much lower mortality rates than native-born New Yorkers in
1910 , but a few pages later are presented as the reverse in 1890 . Why? The answer probably has to do with the reliability of the figures rather than the living conditions or health care of New York Italians, but we are never told. Throughout the volume, statistics are there to illustrate the social picture rather than to provide the starting point for analysis. Nevertheless, Kraut has a sharp eye for poignant detail and brings to life the individual stories of a few of the millions who made the journey.

In the 1903 Book of Instructions for the Medical Inspection of Immigrants, tuberculosis was a "dangerous contagious disease". Available methods of detection meant that few people were turned away because of it, but tuberculosis rates were high among immigrants and firstgeneration urban Americans. Some of these feature in Sheila Rothman's moving account of what it was like to live in the shadow of death. By the early twentieth century, Robert Koch's discovery of the tubercule bacillus had transformed perceptions of the disease from a constitutional, familial one to a contagious disorder best dealt with through isolation. In the transformation from consumption to tuberculosis, invalids became patients.

Rothman structures her narrative into three parts. The first, from 1800 to about 1870 , deals with middleclass New England consumptives coming to terms with the probability of a shortened life of invalidism. Medical advice and conventional wisdom led the men to seek recovery through a sea voyage or wintering in warmer climates. Moderate exercise and fresh air were also deemed good for weakened lungs. A few women also went along the same path, but travel for women with domestic responsibilities was difficult. Rothman captures the varieties of the male experience through the diaries and correspondence of many young men; the female is encapsulated through the brilliantly constructed story of Deborah Vinal Fiske (1806-44), whose confidante and fellow sufferer Harriet Webster Fowler followed her to the grave six weeks later.

Fiske's daughter, Helen Fiske Hunt Jackson, lived longer than her mother but she, too, was consumptive. She died in Colorado, where, along with Texas, Arizona, California and other western states, tubercular health-seekers settled in large numbers after the American Civil War. They were generally tended by doctors who had gone west for the same reason: consumptives caring for consumptives. The promotional literature encouraged those with weak lungs to head west: "the Texas air I think beats any fattening compound I have tried for the last ten years", wrote Dr Boyd Cornick, who eventually set up his medical practice in San Angelo, Texas, a few miles from where my ancestors ultimately drifted.

After the voyage, and the west, came the sanatorium, as tuberculosis became a public health issue. The sanatorium movement incorporated many of the older notions of the relationship between climate and lung disease, but the new perception of the contagiousness of tuberculosis transformed social attitudes and underlay new medical powers of committal. By 1925, there were more than 650,000 sanatoria beds in the United States, many funded by charities or municipal health budgets for immigrants.

Eminent doctors or reformers occasionally surface in these two books: Maurice Fishberg, Jacob Riis, Alfred Loomis, Edward Trudeau. For the most part, however, Kraut and Rothman seek to resurrect history's silent majority, to convey what it was like on Ellis Island or in the Adirondack Cottage Sanatorium. Inevitably, perhaps, each volume ends with the historical reverberations of AIDS and the salient reminder that meliorism is a hollow philosophy in 1994.

W. F. Bynum is in the Wellcome Institute for the History of Medicine, 183 Euston Road, London NW1 2BE, UK.

\section{High-tech riches}

\section{DanielS. Greenberg}

Profits of Science: The American Marriage of Business and Technology. By Robert Teitelman. BasicBooks: 1994. Pp. 258. £23.

IN the 1960s, Wall Street called it the "sonics and tronics" boom - the rush for shares in companies radiating prospects of mammoth returns from the new gold fields of the United States, laboratories in the service of electronics and its associated industries.

Some early arrivals on the industrial scene, such as Texas Instruments, Xerox and Digital Equipment Corporation (DEC), fulfilled the high-tech investment dream, at least for many years, and others followed, such as Apple, Microsoft and Intel. Within a decade, DEC's initial backers reaped a 5,700 per cent return on investment. Unable to compete with this new way of creating wealth, some of the 
famous old names of industry disappeared in great upheavals of money, marketing and technology, among them DuMont and Philco, powerhouses from the early days of radio. Mighty RCA, the giant of television innovation and sales, sold out to General Electric.

Two decades later there seemed to be a replay of corporate birth and growth in the life sciences, as investors responded to reports of an onrush in biotechnology that would even dwarf the spectacular triumph of electronics. "Biomania" was the term for this marketplace phenomenon, highlighted in 1980 by the initial public offering of shares in Genentech, a company with great promise but virtually no income. Genentech came on the market at $\$ 35$ a share and 20 minutes later had ascended to $\$ 89$. A decade later, Genentech, no longer the darling of Wall Street, entered into a corporate relationship with Hoffmann-La Roche to finance the difficult quest for profitability from biotechnology. Other companies in the biotechnology sector also soared in share price at the start, and subsequently went out of business or sold out to the established powers of the pharmaceutical industry.

The dynamics of these successes and failures is the subject of Profits of Science, an ambitious study that confronts the elusive relationship of finance and science and technology in the new postwar industries. Robert Teitelman, a senior editor at Institutional Investor magazine, is a knowledgeable guide through the finances and technologies of the centrepieces of this account: electronics, pharmaceuticals and biotechnology. Along the way, he also reaches for an understanding of the contributing roles of scientific progress, entrepreneurship, government policies and Wall Street's herd behaviour. Relying heavily on published sources, both scholarly and journalistic, this is a lucidly written work of interpretation, though in the end the author confesses his own puzzlement about many aspects of the dynamics of the high-tech economy.

The stage in Teitelman's technoindustrial dramas is dominated by finance - its availability, cost and accompanying conditions. The role of money is repeatedly emphasized as the most influential variable in product development, manufacturing and marketing. "It is a mistake to view technologies as if they were isolated phenomena, rising as if by spontaneous combustion", he states. "Rather, they are built on a scientific base, shaped by the financial environment." And he goes on to argue that "Cheap, available capital can shrink the gap between science and technology, accelerate change, undermine the hegemony of the large corporations, and occasionally hold off the shadow of maturity. Large reserves of inexpensive financing can allow smaller, newer companies to exploit scientific pos- sibilities earlier." If the science yields technology, as it so abundantly did in electronics, the small fry can prosper, Teitelman points out. But not so if the science remains recalcitrant, as has been the case so far in biotechnology - a scientific triumph yet to find great marketplace success.

As a case in point, Teitelman chronicles the postwar triumph of the transistor over the venerable vacuum tube, a victory produced by science-based technology, abundant venture capital and nimble management. Although "the vacuum tube industry was confident of its staying power" and even developed and marketed some transistor products, he says, "the smaller companies proved to be more aggressive marketers - - they had no vacuum tube business to defend - and they were more effective in sniffing out and providing what the market needed and wanted".

In the postwar period, he observes, the unprecedented abundance of government research funds enriched the scientific and technological atmosphere, loosened a gusher of venture capital and spawned the creation of innumerable start-up companies that "surfaced in great waves, many with a technological mission and a zeal for competition. The ready availability of capital brought these new players more time to commercialize new technologies, to develop new products and skills (marketing, manufacturing, management) that had traditionally allowed larger corporations to preserve their position in a dangerous, unstable world."

Interacting with the availability of capital, he writes, is the state of the science that underlies the technology, and these factors, in turn, shape the corporate structure and managerial style of commercialization attempts. "Generally speaking, the ease with which a technology is commercialized varies with the maturity of its underlying science .... The bureaucratic structure of most major drug companies and of drug regulation was formed, in part, as a response to the stubborn uncertainties of drug discovery and biology ..... The scarcity of venture capital in the early 1950 s meant that television makers came predominantly from the ranks of prewar radio companies; the flood of equity capital in the 1980 s floated many new computer and semiconductor firms, despite the daunting costs."

Teitelman is particularly incisive about the transition in research politics wrought by the postwar infusion of government money into academic science. From the late nineteenth century to the early $1950 \mathrm{~s}$, he points out, "the technological economy was dominated by a handful of giant companies: AT\&T, General Electric, RCA, Westinghouse, Du Pont". Buttressed by economies of scale and ample corporate treasuries, these companies "deployed their financial muscle to build patent fortresses, heavily influenced the government's R\&D [research and development] and regulatory agendas, and, again through the power of the purse strings, held the greatest sway over academia". By the late 1950s, however, federal funds provided an alternative to industrial financing of university research, while small companies proved to be particularly fruitful settings for developing and commercializing electronic products.

As should be evident by now, Teitelman crams a great deal of fact, argument and interpretation into a modestly sized book. He is strong on insights, asking, for example, who on bedazzled Wall Street "really knew what was happening inside Texas Instruments not to mention at newer, smaller, more obscure firms?" The answer is that once share prices took off, few cared. But whether the grand themes of technology, finance and industry that he presents hold up under scrutiny is another matter.

Oddly enough, he concludes on a note of doubt, asserting: "The system that has developed in the United States is one of great complexity, constant change, and feedback. Quantification is difficult (though by now, great effort has been put into quantifying technological inputs and outputs), and one is left with description and portraiture."

True. Still, this is a commendable book, particularly worth reading in the current context of deliberate government efforts, in the United States and elsewhere, to cultivate high-tech riches.

Danie/ S. Greenberg is editor and publisher of Science \& Government Report, 3736 Kanawha Street NW, Washington DC 20015, USA.

\section{New in paperback}

Irrationality: The Enemy Within by Stuart Sutherland. "A lively and readable book about modern follies" (Ernest Gellner, Nature 360, 384; 1992). Penguin, £6.99.

Making Silent Stones Speak: Human Evolution and the Dawn of Technology by Kathy D. Schick and Nicholas Toth. Simon and Schuster, \$13. "Lively", "fascinating" and "up-to-date" (John Gowlett, Nature 362, 672; 1993) Genius: Richard Feynman and Modern Physics by James Gleick. Abacus, $£ 8.99$. A "moving, beautifully written, literate and perceptive account" (S. S Schweber, Nature 360, 375; 1992).

Science and Technology Advice to the President, Congress, and Judlclary (2nd edn) edited by W. T. Golden. AAAS Press, $\$ 29.95$. Contains 85 brief but

informative essays, including one by McGeorge Bundy (see page 365 for his review of James B. Conant). 